\title{
The ethics of telling the patient
}

\author{
Lawrence Goldie Royal Marsden Hospital, London
}

\section{Editor's note}

The author, a consultant psychotherapist who works with dying patients in a National Health Service (NHS) hospital, argues that the moral issue is not simply whether or not to tell cancer patients the truth, but more importantly how to do so. Lies and the bald unprepared-for truth may both be damaging. Time and trouble is needed to understand patients and help them understand their situation. Dr Goldie warns that putting oneself into the patient's shoes, as doctors so often do, is the best way of not knowing what another feels. Such misunderstanding may lead to medical decisions based on 'nothing more than fantasies - uninspired guesses about what other people think and feel. It is the equivalent of prescribing for patients without examination'.

The question whether or not to tell a patient the truth usually arises in connection with cancer. One would expect it to arise with other diseases but it does not do so. There does not appear to be the same debate about telling patients they have disseminated sclerosis, or coronary disease as there is with cancer. The issue, therefore, is not simply a matter of telling the truth it is a matter of telling the truth in one circumstance and not in another. Thus what the word 'cancer' signifies to the patient is supposed to influence the doctor in his decision to lie about the diagnosis. In fact I believe the decision is more influenced by the doctor's own feelings about cancer than by the patient's. Virtually all patients attending for diagnostic, exploratory, or other procedures, in the early stages of any malignancy, have in mind the possibility of cancer. The doctor's decision, therefore, is not whether to tell the patient the truth, or to deny it, but whether to play out a charade, with the patient, of normal life and prospects, in the presence of incontrovertible symptoms and signs of the growing cancer. The charade may include other players; a surgeon may tell a spouse not to use the word cancer to the patient and urge a pretence that it is something else by using words like, 'lump', 'ulcer',

\section{Key words}

Medical ethics; terminal diseases; truth telling; lying. 'abscess', 'blockage', with an added diminutive as in the phrase 'it's just a little growth'. This may mean, for example, a patient knows that his wife knows, but they do not speak of it to each other! The doctor's decision to initiate this restriction on free speech, and the truth, disrupts any normal intercourse, so that couples instead of growing together, wither in each other's arms.

In many diseases the doctor, not necessarily concerned with the truth for its own sake, may press home 'the truth' in order to induce patients to submit to unpleasant procedures that they would (it is presumed) wish to avoid. Less commonly and with less effect it is used to induce a patient to change from a destructives way of life. For example, an attempt may be made to activate an obese, physically inert individual into con structive adaptations after a heart attack, by telling him he is in grave danger if he does not change. With cancer, however, a point is commonly reached when it is believed that nothing more can be done by the patient or the physician, to alter the course of the disease. This is also the case with, for example, multiple sclerosis, where there is no alteration in life-style that we know of which can materially alter the progression of the disease. However, the patient is generally told the truth, though the manner of dying is more likely to be painful and difficult than it is with most forms of cancer. What a patient is told about the diagnosis and outlook may be determined by the fantasies about the illness and reactions to it in both physician and patient, rather than by the nature of the illness itself. Physicians may know the actuarial realities of a disease, and its outcome, and they may use these to avoid describing the various real-life scenarios that characterise life with a particular disease. The statistical prognosis may be used to justify optimism, and a particular form of treatment. This is the most pernicious form of lying because the statistical 'odds' do not tell people what they really want to know: their personal prognosis. At best this ploy encourages a short-lived gambler's euphoria.

The medical attendants have fantasies about the consequences of telling the truth, and this often determines their behaviour in the presence of patients. The most common 'philosophy' for action is to avoid mentioning the worst for as long as possible. The 'worst' 
often being an eventuality, if the patient and his or her resources are unknown to the doctor, conjured up in fantasy. For example, Lyn came from another hospital, where she had attended but had refused to continue. She was a young woman of 22 , who had been studying physiotherapy before she got married. After her first baby was born she diagnosed that she had cancer of the clitoris. She told the surgeon this before biopsy and operation. When she arrived on the ward, prior to operation, she so dismayed the ward sister by telling her the diagnosis, that the sister asked immediately for an inquiry to find out who was responsible for her knowing the diagnosis. At a later date the patient saw another doctor for radiotherapy, and he infuriated her by trying to persuade her that she was mistaken in thinking that she had cancer, and by putting on an act that she thought was an insult to her intelligence and character. She was so hurt and mortified that she refused to re-attend that hospital. Once during a discussion with the author she said that 'patients' should be told the truth . . . she then had to stop short and she paused as she absorbed the truth, the truth about herself, she actually had cancer. She was a patient. Transiently she said that she had felt that she was discussing something that happened to other people. She went on to describe how her father had died when she was 12 years old of cancer of the lung. Her mother was told not to let her husband know. Her mother was still distressed and guilty at having obeyed this injunction. She still wondered what her husband had thought and needed. The patient felt that the conspiracy of silence had prevented them from sharing his most intimate thoughts and she still wondered if her father had wanted to say something special to her before he died. Lyn was intelligent and sensitive and I was asked to see her because it was thought that, knowing her condition, she would become depressed. She discussed her life without reproach. She was sad without being persecuted or resentful. She could manage her pain, her discomfort, and her relative isolation, without anyone, but she seemed to value the discussions. Though it was a privilege to talk to her, few had the courage to do so and significantly nurses, all her contemporaries, rarely chatted with her, presumably because they were frightened of the challenge she presented, knowing her diagnosis and too readily seeing themselves in her place.

A patient may be given bad news in many different ways - none can make it good! Patients may be told without having to ask questions or they may be told the truth in response to a question. Should people be told that their remaining life is very limited, and the way it will end, even if they do not ask? Alternatively should they be told in order to give them the opportunity to discuss their life and its future? The patient may need to make various arrangements and preparations for his or her demise. Is it then ethical or fair to decide, without the patient's knowledge, what he should or should not know about his own life? Is it right to assess a personality, and its potential, without knowledge of its strengths and weaknesses, after a brief contact arranged for an entirely different purpose? The position is rather similar to knowing that an individual is going to have to perform a task requiring considerable fortitude and endurance. The individual is kept in ignorance of the true nature of the task on the grounds that it is best not to anticipate an unpleasant experience, so that the individual is shocked and unprepared for what then transpires.

The truth can be told in many ways and there are many variations in the circumstances of the telling. Should people be told the frightening diagnosis bluntly and plainly in five spare minutes in a busy out-patient clinic? With no time to give comfort and help them cope with the aftermath or for further questions? Or is it better to tell the patient in conditions of privacy, where time has been allocated and protected in advance (by ordering an embargo on calls and interruptions, for a specified time)? Doctors in general do not know how to pace themselves, and to generate excitement and an appearance of Herculean labours coped with heroically they appear nonchalant and are eventually careless of other people's time. For instance, some out-patient departments are full because a doctor, careless of public dignity, has made 50 appointments at one time. This also has the effect of embarrassing patients into silence and leaving no time for questions.

The truth may be told quite plainly, the diagnosi being given baldly without preliminaries, or questions On the other hand a patient may use a pause or diffidence in the doctor and ask 'Have I got cancer?', or 'Am I going to die?'. The response to these questions may be mature consideration and simply, 'Yes', or 'No'; or 'It would appear to be so', or 'What do you think?'. Despite the doctor's fantasies about what he would feel in the circumstances, there can be a presentation of the truth by simple statements, refusing to deny what the patient already knows, and with gentleness, compassion and sensitivity, following the patient's lead as he tries to live with the doubts raised by the disease. One patient for example, not suspecting that anything serious was amiss, went to hospital for 'blood tests'. Subsequently, because of the nature of the results, an appointment was made for him with a physician. Without preamble the consultant presented him with the news that he had a very serious form of leukaemia! The patient collapsed and was incontinent of urine and faeces. One might surmise that had the patient been told by his general practitioner what was being considered and had he had an opportunity to discuss the various eventualities he might not have been so defenceless.

I was taken by surprise when $\mathrm{Mrs} S$ was pushed into the consulting room in a wheelchair. I had not read her case notes or the referral letter. Her husband, who had pushed the chair, disappeared as he closed the door behind her. She was slumped, crumpling in her wheelchair, haggard, grey, and emaciated: a woman in her early forties, obviously a shadow of her former self, 
whimpering with despair. Her first words were, as if surprised and incredulous 'I am not getting any better?' I said, 'It does not appear so'. She said 'I am going to die then?' and I said 'Yes ....' She said 'Soon?' I said 'Yes, but I do not know when . . .' She said 'I want to be here for my grandson's second birthday'. I asked when that would be. She said 'At Christmas time'. That was approximately five months away. I said that I did not know whether that would happen. This interview took an hour. During it she visibly altered, she straightened up in her wheelchair, and her demeanour changed. She stopped whimpering, and the conversation after these initial exchanges, took quite a different direction. She reviewed her past, and the ways in which she had been fortunate. She had had two sons who had just missed being old enough to have been in World War II. The transformation was remarkable, true hope and optimism replaced despair. She was asked why she had in the past seen several psychiatrists. She said that in her younger days she had become depressed at one time, and her general practitioner had referred her to a psychiatrist. As a result she saw eight psychiatrists, but none of them had spoken to her for more than ten minutes at a time, and the treatment had consisted mainly of the prescription of various tranquillisers and anti-depressant drugs.

Subsequently, whilst her physical condition deteriorated, the patient developed and her relationships with other people burgeoned. She succeeded in repairing damaged relationships and resolved a family feud. She had a steady stream of visitors, and was forthright in urging them not to use euphemisms, but to speak plainly about her illness. She told them that she knew what it was, and she knew that shortly she would die. It was interesting to note that one nightnurse so enjoyed the patient's company that she often visited her in off-duty time. When medical professionals speculate on whether patients should be told the truth or not, they rarely have this type of experience to draw upon. Their judgment is then based upon fantasy, usually generated by putting themselves 'in the patient's shoes', presuming that they know the patient's mind.

In another instance the psychotherapist was asked to see a patient because she was due to have a severely mutilating operation in three days' time. The psychotherapist arranged for the operation to be postponed, to give the patient time fully to appreciate and discuss the consequences of the operation. She had a carcinoma of the tongue. To remove it would involve the sacrifice of all or part of the tongue, and part of the jaw. Subsequently there would be several plastic procedures to remedy, partially, defects in the skin and bone of the jaw. The patient discussed the operation with the surgeon and separately, with the psychotherapist. It was thought that operation would make the terminal stages of the disease more bearable: the surgical justification for the operation was not to prevent the lesion from extending or spreading. What the patient was told appeared to be the truth, and she made her decision. But she was not told the whole truth. The patient was told that surgery was an attempt to get rid of the disease and that there was no certainty that it would do so. The whole truth was in fact that whether the patient had the operation or not she was almost certain to die from an extension of the cancer. The various options and eventualities, and the price to be paid in deformity and suffering, for the dubious benefits of the operation were not discussed. The sister, an expert in nursing such patients, had no doubts that she herself would not have had the operation. But because the patient was not told the whole truth her lips were sealed, and she supported a course of action she did not believe was constructive. One can only speculate as to what she would have told the patient before operation.

Medical training advocates that the scientific method should be applied in clinical medicine, the aim being to provide conditions that enable observations by one person to be repeated by different observers at another time and place. The doctor looks for signs and symptoms of a disease seen elsewhere at other times by others, so that what has been observed in an experiment to alter the course of the disease can be repeated. Unfortunately this has encouraged clinicians, who are generally inept and gauche when it comes to observing and studying psychological phenomena, to ignore the whole person, to dispense 'psychology' in a few favourite aphorisms, and then to concentrate exclusively on the physical. Generalisations about disease, and particularly about physical signs and symptoms, can be useful, according to this 'scientific' approach, whereas generalisations about personality, character, and emotions are generally misleading, though seductive. But psychological phenomena, though they are far more complicated, can be usefully observed and categorised, though this requires different gifts and different methods from those a doctor could be expected to have. The first real attempt to do this observing and categorising was made using the psychoanalytic method. This method has since led to an approach which may be designated 'the psychotherapeutic approach'.

The object of enquiry here is the mind, and its contents, and physical methods of investigation are inappropriate. Furthermore, the investigators are both the patient and the psychotherapist, partners in the endeavour to obtain a true appreciation of what is in the mind. In studying human beings the scientific method attempts to eliminate the influence of the 'subjective factor'. Psychoanalysis and psychotherapy make the subject - the person - the observer of feelings, the object of study. The process is difficult, requiring talent, skill, experience and technique, the patient being both an observer and also an unwitting source of distortions of the truth. A patient may seem to be giving an account of his feelings, yet, wishing to deny their significance, he may play some down and exaggerate others. Obviously the 'observer' will be changed, and the powers of observation reduced by anything 
which suppresses the brain. Drugs, toxins or alterations of body chemistry which cloud consciousness, or produce disinhibition will alter the ability to perceive and the capacity to distinguish between 'inside' and 'outside' in the mind. The skill of the physical scientist is evident in the way in which he asks his questions. Questions are formulated so that an attempt at answering them can be made and the very attempt results in new information being acquired. The main reason for using this method is because it works but the motive can be anything from the wish simply to discover the truth (pure research) for its own sake, to wanting to make money by finding products that can be sold profitably or to wanting to make more efficient instruments for destroying life (invention and applied research). Psychoanalysis may be likened to pure research (as opposed to applied research, equivalent to symptomatic treatment) and is an attempt to know the truth about what goes on in the mind. Psychotherapy, however, uses the psychoanalytic technique in searching for the truths which will help people to reduce unnecessary suffering and survive it when it is inevitable. The therapist with conviction based on experience believes that this is the best way of helping individuals cope with unease, or disease. From this point of view it would be unethical to help the patient or anyone else to obscure, fudge, or distort the truth. In practice it is both honest, and reassuring to patients, for them to be told that this is the ethic and aim of the procedure, the psychotherapeutic endeavour. Obviously one would not begin to seek out and display the truth without undertaking to remain with patients whilst they digest and assimilate it: to do otherwise would be like performing a skilful surgical operation and then leaving the skin unsutured, the wound uncovered, and the patient deteriorating. For the purposes of treating the disease the scientist/doctor must know the truth about the physical processes in order to treat and to have the ability to predict to some extent the course of events. Is it ethical to do so without letting the patient know what is believed to be going on in his body, what risks he is taking, and the future that is being planned for him? It would be like having an expert in to examine the water system in a house without being told what the expert finds, what he intends to do about it, if anything, what the consequences will be for the householder, and above all the cost. It would be intolerable, yet this is sometimes the position of the patient in relation to the medical expert. He is deprived of the privilege of knowing, in terms that he can understand, what the expert thinks and prognosticates. The expert then decides his fate without knowing the patient's character and strength - the doctor may think that he knows, having put himself in the patient's shoes, but that is the best way of not knowing what another feels! Psychotherapy, if it succeeds in making the truth available, gives patients the freedom, if they want to use it, to act and to take responsibility for their future.

Most doctors, if asked about their hospital work, would give quite a sensitive account of the dramas played out in the hospital and in their work. For the most part they would feel that they know how they appear to patients, and would probably have very definite ideas about how they should and do behave towards patients. As Balfour Mount has shown, this is erroneous (I). But they have not considered themselves as victims of the covert destructive limiting forces in a hospital. These forces, in the form of social and group pressures - can severely restrict freedom of thought and action. They arise especially when groups of people feel exposed and vulnerable. Living with doubt and uncertainty leads to denial. In war-time this was seen in the humour of the air-raid shelters; the apparent nonchalance of airmen - death-dealing and facing death. (Part of this process was the brilliant and officially encouraged RAF magazine Tee Emm. Full of ironic and at times macabre humour with the bawdiest of origins, it contributed dozens of colourful phrases and idioms to every-day English). Wards for patients with muscular dystrophy - virtually all boys, with none surviving beyond the age of 18 (exceptions reach 20-22 years of age) sometimes have the atmosphere of an air-crew mess. Patients are calm and cheerful, with the weekly news of someone who has not survived the weekend producing a wry comment and barely a ripple in the organised surface of routine and bonhomie. For less constructive purposes the same denial operates in the staff of other institutions. In psychiatric hospitals in the Soviet Union which incarcerate dissidents and political opponents of the regime, the staff exonerate themselves from blame by denial co They deny that anything destructive is happening by? attributing destructiveness to the victim, or they justify their participation on the grounds that they as individuals are powerless to alter the system by influencing colleagues or superiors or disobeying orders. The arguments and rationalisations have a familiar ring because they are ubiquitous defences against truth and depression. The hospital, where life and death issues condense and concentrate, produces similar reactions in the staff.

In the presence of pain, imminent death and mourning there can be amongst staff a cheerful appearance of dealing with the commonplace as if they have no responsibility for what is happening. Nurses cannot help what doctors do, or fail to do. Doctors cannot act without a superior's permission and superiors feel that they cannot change the system, claiming to be victims of the administration, the political system or inept colleagues. Solzhenitsyn in The First Circle describes the tremendous effort needed by 'victims' of the system to retain their integrity and independence of thought. The forces that coerce and seduce staff are in proportion to the presence of unrelieved stress. Hospital personnel react in a quasi-military style: uniforms, ranks and deferential treatment of staff high in the hierarchical system are how they are ruled. General hospitals manifest such denial and specialist hospitals which produce an overwhelming concentration of feared conditions have even more hidden but rigid ways of preventing the emergence of doubt, fear and 
independence - like the 'specialist' in The First Circle prison of Solzhenitsyn's account.

The hospital produces imperceptible measures to encourage compliance in the patient and the minimum of awkward self-appraisal in the staff. This can be very tortuous. For example, it may become undeniably evident that the large number of patients who have cancer of the breast need something extra by way of consideration of their feelings. The staff, medical and nursing, acknowledge the need, create a post - with a new title, and fill it with a member of the staff. The staff member is no better equipped for the work than anyone was before the new slot was created and he or she continues to do what nurses and medical staff should be doing anyway in their traditional roles. The important function of the manoeuvre is to deny that there is a special need which none of them are satisfying. This need should be met by a specially trained person, appropriately orientated by vocation and training, being brought in to attend to those areas of care and concern which are being neglected. As far as the new appointment is concerned the fear is of the unknown; medical staff fear an approach of which they have no knowledge - they react as if issues are going to be raised and forces unleashed which they cannot control. Hence new appointments are given to controlling figures who can be understood and identified with. In the cancer hospital the 'military' state of mind is evident in the jargon which is in fact used in describing 'aggressive' treatment regimes against 'invasive' or aggressive disease. The word 'cancer' is avoided by referring to 'the disease'.

A young man had a recurrence of a cerebral tumour and became morose and depressed. It was feared he would commit suicide, though he had never expressed this intention. This presumption (or fantasy) was not based upon actual knowledge of what the patient had in mind. It seemed so obvious and certain, that no one asked what he thought and he was never left alone. With ingenuous frankness he opened our conversation by saying that he had just been to Paris and when he went with a prostitute found that he was impotent. He could not masturbate either and this dismayed him. He was also very upset because he had interrupted his career to come to this country to have the operation to remove the tumour. By now his fellow medical students would be well ahead of him. Thus the staff by putting themselves in his shoes had misconceived his thoughts and intentions - worse still, their certainty that they knew what he was thinking meant that no-one inquired! Subsequently the patient left the hospital, and as an out-patient became engaged in psychotherapy with interviews four to five times weekly. His mood changed, he took up swimming and squash again. After six months he re-applied for a university place and was accepted. This young man, with a serious physical condition, is not so concerned by it as he is with what are for him much more important problems. On the ward he became a victim, literally a prisoner of the staff's delusions. He was not given the opportunity to say what he thought. The psychiatrist was asked to see him merely in order to effect his transfer to a mental hospital. In other words the patient stood accused without knowing why.

These 'Kafka-esque'. situations arise because the 'carers' have fantasies about cancer and death and in enacting them may make the unwitting patient suffer. This is a very common situation and patients react to these implicit accusations and delusions about themselves in a variety of different ways. The patients may respond by trying themselves to make 'sense' of incomprehensible behaviour and messages. Some patients are often described as 'paranoid' when in fact they are suspicious with good reason. The most common situation is where patients are bewildered. No one has discussed with them the nature of their disease and yet they are subjected to various investigations. The most common reason given for failing to discuss the disease and possibilities with the patient is because the investigations are not completed. In fact the truncated conversations on ward rounds and the vagueness of replies to their questions (to avoid being committed) leave patients bewildered and suspicious. Even when the news is bad, patients often express relief because the truth removes doubt and gives them a rational explanation for the investigations and for the concern of their doctors. Apart from the painful feeling of being excluded, patients are, by these devices, prevented from considering and influencing their own future. People who are seriously ill for the first time may be worrying about their home, particularly if they live alone. They may wish to plan for the benefit of relatives if the treatment is going to be prolonged. Social workers, if available, may not be able to discuss alternative arrangements because the medical or surgical teams have not committed themselves to a diagnosis and prognosis. The length of time they will be in hospital, the degree of incapacity they can expect and the probable length of life is unknown, undiscussed and imprisoning. This is unethical interference with patients' lives. Their freedom of choice is by these means taken away from them. Thus patients in these circumstances are inadvertently made into prisoners, with others deciding their fate.

The last case illustrates rather painfully some of the consequences of doctors and nursing staff acting upon what are nothing more than fantasies - uninspired guesses, about what other people think and feel. It is equivalent to prescribing for patients without examination. Mr P decided, when his cancer of the oesophagus was discovered, to forego any treatment for it. A year later he was referred to the psychotherapist because he was thought to be 'depressed'. When interviewed it turned out that he was depressed because his vision was blurred and he could not co-ordinate sufficiently to write. And this, it turned out, was due to the sideeffects of three drugs which were 'anti-depressants' and 'tranquillisers' and three drugs which were for the relief of pain. He had been given these drugs because it was presumed that he would be in pain, yet he said he had never complained of pain. The tranquillisers were 
given because it was thought he would be anxious as death was close. He said that he was not afraid of dying but he was concerned about the possibility of dying through choking, with no relief available. In effect he had been given drugs without having a condition which required them, and his ability to think and act as he wished, constructively, had been taken away from him. He had not been told what the drugs were for and they had in effect imprisoned him in a nightmare. All these drugs were stopped and he went home. There, he went over the household affairs with his wife, teaching her how to do many of the odd jobs that he would have done, as he anticipated that on her own she would not call in an electrician, for example. He taught her how to change a fuse and to understand the ring main. Several months later he phoned in saying that he "had had enough'. He was admitted and his oesophagus was virtually closed off. He could just swallow a teaspoon of fluid. He was still a well nourished robust-looking man, and it was as if having completed his task there was nothing more to do, and on his third day after admission he died - peacefully.

Sometimes the hospital, or part of it, can become like a totalitarian state, with a limitation on the subject's freedom to think and act independently. Perhaps as a legacy from the days of the poor law institution, when medicine was a charity and patients were expected to be deferential and effusively grateful, so sometimes today patients may be treated as if they were privileged to be in the hospital at all and receiving treatment. In fact it is the healthy doctor or nurse who are the privileged parties as they are by chance healthy, and free to be of service to those less fortunate. One feels that what was once urged in retail shops by progressive and enterprising shopkeepers ought also to apply in a hospital: 'The customer is always right!' So too the patient is always right, including the patient who complains and the patient who complains too much: indeed the latter may be a patient just because he complains 'too much'.

Meeting a 'patient' is a very special event, a transaction to be handled with great care. The 'patient' in most instances cannot escape the meeting. As the nurse or doctor one is empowered and able perhaps to impose oneself, awkward and inept, on another. Patients have the power to refuse others entry into their world - but because they hope something good will come of the meeting and to avoid hurting another's feelings they hide their misgivings. Staff may thus be misled, and being preserved from self-knowledge by the sheltering title, and position, stalk the wards unaware of the tolerance they are being shown. Often they are manifestly eccentric, assuming as they pontificate, that they are superior to the row upon row of horizontal ordinary folk, casualties precipitated into vulnerability. The caring professionals, the healthy ones, are in great danger, for their characters become shallow and fossilised if they fail to realise their humble position - and their privilege.

\section{Reference}

(I) Mount B M. Death and dying - attitudes in a teaching hospital. Urology 1974, Dec; Vol 4, No 6. 